\title{
Response: Commentary on the effects of hypoxia on energy substrate use during exercise
}

\author{
Alex Griffiths ${ }^{1 *}$ (D), Oliver Shannon ${ }^{1,2}$, Jamie Matu ${ }^{3}$, Roderick King ${ }^{1}$, Kevin Deighton ${ }^{1}$ and John P. O'Hara ${ }^{1}$
}

\begin{abstract}
Background: A recent commentary has been published on our meta-analysis, which investigated substrate oxidation during exercise matched for relative intensities in hypoxia compared with normoxia. Within this commentary, the authors proposed that exercise matched for absolute intensities in hypoxia compared with normoxia, should have been included within the analysis, as this model provides a more suitable experimental design when considering nutritional interventions in hypoxia.

Main body: Within this response, we provide a rationale for the use of exercise matched for relative intensities in hypoxia compared with normoxia. Specifically, we argue that this model provides a physiological stimulus replicable of real world situations, by reducing the absolute workload undertaken in hypoxia. Further, the use of exercise matched for relative intensities isolates the metabolic response to hypoxia, rather than the increased relative exercise intensity experienced in hypoxia when utilising exercise matched for absolute intensities. In addition, we also report previously unpublished data analysed at the time of the original meta-analysis, assessing substrate oxidation during exercise matched for absolute intensities in hypoxia compared with normoxia.
\end{abstract}

Conclusion: An increased reliance on carbohydrate oxidation was observed during exercise matched for absolute intensities in hypoxia compared with normoxia. These data now provide a comparable dataset for the use of researchers and practitioners alike in the design of nutritional interventions for relevant populations.

Keywords: Altitude, Carbohydrate, Fat, Oxidation, Relative, Absolute, RER

\section{Background}

The authors welcome the constructive feedback provided by Young et al. [1] regarding our recent meta-analysis [2]. Their critique relates to the validity of practical/nutritional applications for relevant populations when informed by substrate oxidation responses during exercise matched for relative intensities in hypoxia and normoxia (i.e. exercise is conducted at the same percentage of altitude-specific $\left.\dot{V} \mathrm{O}_{2 \max }\right)$. Young et al. [1] suggest that as any given workload in hypoxia requires the same absolute energy requirements as normoxia, nutritional strategies for relevant populations should be informed by substrate oxidation responses during exercise matched for absolute intensities in hypoxia and normoxia (i.e. exercise is

\footnotetext{
* Correspondence: A.Griffiths@leedsbeckett.ac.uk

${ }^{1}$ Research Institute for Sport, Physical Activity and Leisure, Leeds Beckett University, Leeds LS6 3QS, UK

Full list of author information is available at the end of the article
}

conducted at the same absolute workload in hypoxia and normoxia). However, as the relative percentage of $\dot{V} \mathrm{O}_{2 \max }$ utilised during sub-maximal exercise of the same absolute workload is higher in hypoxia compared with normoxia [3], muscle metabolic perturbations are increased. Specifically, finite metabolic substrates such as muscle glycogen and phosphocreatine are degraded, subsequently elevating the accumulation of fatigue-associated metabolites such as $\mathrm{H}^{+}$, inorganic phosphate and adenosine diphosphate [4]. This effect is potentiated in hypoxia compared with normoxia when using exercise matched for absolute exercise intensities. For reasons discussed below, it is our view that the use of absolute exercise intensities and the associated physiological stimulus do not reflect real world applications, and the use of exercise matched for relative intensities under the same metabolic stimulus is more appropriate.

(c) The Author(s). 2019 Open Access This article is distributed under the terms of the Creative Commons Attribution 4.0 International License (http://creativecommons.org/licenses/by/4.0/), which permits unrestricted use, distribution, and reproduction in any medium, provided you give appropriate credit to the original author(s) and the source, provide a link to the Creative Commons license, and indicate if changes were made. The Creative Commons Public Domain Dedication waiver (http://creativecommons.org/publicdomain/zero/1.0/) applies to the data made available in this article, unless otherwise stated. 
In order to understand the utilisation of each substrate during exercise at high-altitude (and therefore determine nutritional interventions), it is necessary to isolate the effects of hypoxia (as per relative intensities), rather than the effect of an increased exercise intensity (as per absolute intensities). During high-altitude sojourns, exercise is not performed at increased exercise intensities, as induced by exercise matched for absolute intensities. As a result of physiological and psychological factors, highaltitude mountaineers, military personnel and athletes exercise at a reduced absolute workload, to compensate for the reduced oxygen availability experienced at highaltitude, thus matching the same relative exercise intensity in hypoxia compared with normoxia. Therefore, for ecological validity, we believe nutritional interventions should be informed by exercise matched for relative, rather than absolute intensities in hypoxia and normoxia.

In order to justify the use of a specific model, it is important to determine the differences in substrate oxidation between exercise matched for absolute and relative intensities in hypoxia and normoxia. In addition to the important narrative synthesis provided by Young et al. [1], it is necessary to summarise these findings in a systematic and quantitative manner. As such, we will report and discuss previously unpublished data from our metaanalysis regarding substrate oxidation during exercise matched for absolute intensities in hypoxia, compared with normoxia.

\section{Methods}

Methodological details (literature search, inclusion criteria, data abstraction, risk of bias, statistical analysis) of the meta-analysis have been reported previously [2]. The sole difference between data reported in the present manuscript and previously published data is the use of exercise matched for absolute, rather than relative intensities. In brief, included studies were required to measure respiratory exchange ratio (RER) and/or carbohydrate or fat oxidation. These measures were required to be quantified during exercise in both hypoxic and normoxic environments. Normoxic trials were required to provide a viable within-subjects control (i.e. equivalent measure(s) quantified in the same participants). In order to maintain a comparable dataset to previously published data [2], the search dates for the present manuscript were not updated. Albeit, the recent papers by Young et al. [5] and O'Hara et al. [6] were included in the discussion of these data.

\section{Results}

A total of 1743 studies published in peer review journals were identified through database screening as part of the full meta-analysis (relative and absolute intensities). Following the screening process, a total of 6 studies utilising exercise matched for absolute intensities in hypoxia and normoxia were identified as suitable for the metaanalyses. A total of 23 comparisons were made for exercise matched for absolute intensities (RER $=7$, absolute carbohydrate oxidation $=6$, absolute fat oxidation $=4$, relative carbohydrate oxidation $=3$, relative fat oxidation $=3$ ).

Tables 1 and 2 present changes in RER and substrate oxidation rates respectively, in relation to exercise matched for absolute intensities.

\section{Participant demographics and study characteristics}

Of the 57 participants included in the analysis, 37 were male $(76.2 \%)$ and 20 were female (23.8\%). Age was reported in all studies and ranged from 22 to 28 years old (mean $=25$ years). BMI was reported in 5 of the 6 studies and ranged from 22.3 to $25.2 \mathrm{~kg} \cdot \mathrm{m}^{-2}$. $\dot{V} \mathrm{O}_{2 \max }$ was reported in all studies and ranged from 2.61 to 4.30 L. $\min ^{-1}\left(\right.$ mean $\left.=3.80 \mathrm{~L} \cdot \mathrm{min}^{-1}\right)$.

Exercise duration ranged from $5 \mathrm{~min}$ to $80 \mathrm{~min}$ (mean $=45 \mathrm{~min})$. Participants in normoxic trials performed exercise at intensities ranging from 46 to $69 \%$ of normoxic $\dot{V} \mathrm{O}_{2 \max }\left(\right.$ mean $\left.=52 \% \dot{V O}_{2 \max }\right)$ and hypoxic trials were performed at $54-82 \%$ hypoxic $\dot{V} \mathrm{O}_{2 \max }$ (mean = $\left.69 \% \dot{V} \mathrm{O}_{2 \max }\right)$. The severity of hypoxia quantified in meters ranged from 2750 to $5620 \mathrm{~m}($ mean $=4200 \mathrm{~m})$.

Mean difference, heterogeneity, sensitivity and moderator analysis for RER

Hypoxic exposure resulted in a significant increase in RER during exercise matched for absolute intensities, compared with normoxia (mean difference: 0.04, 95\% $\mathrm{CI}=0.01$ to $0.06 ; n=7 ; p<0.01$; Fig. 1 ). The degree of heterogeneity was found to be high between studies $\left(I^{2}=98.57 \%, Q=419.47, \mathrm{~T}^{2}=0.001, \mathrm{~d}_{\mathrm{f}}=6\right)$. Sensitivity analysis revealed minor changes only, and these changes did not substantially alter the overall mean effect. Metaregression analysis revealed that no moderators were significantly associated with RER during exercise matched to absolute intensities in hypoxia, compared with normoxia (Additional file 1). Inspection of the funnel plot and Egger's regression intercept revealed that there was little evidence of small study effects (intercept $=8.70,95 \%$ CI: -3.10 to $20.50 ; p=0.12$ ).

\section{Mean difference, heterogeneity and sensitivity analysis for relative carbohydrate and fat oxidation rates}

Hypoxic exposure resulted in a significant increase in relative carbohydrate oxidation during exercise matched for absolute intensities, compared with normoxia (mean difference: $12.1,95 \%$ CI: 8.3 to $16.0 \% ; n=3, p<0.01$; Additional file 2). Sensitivity analysis revealed minor changes only, and these changes did not substantially 
Table 1 Summary of studies investigating the effect of hypoxia on RER during exercise matched for absolute intensity

\begin{tabular}{|c|c|c|c|c|c|c|}
\hline Study & Participants & Study design & Type of hypoxia & Altitude (m) & Duration of hypoxia & RER \\
\hline Braun et al. [7] & 15 (females) & $\begin{array}{l}30 \text { min cycling at } \\
\mathrm{SL}\left(50 \% \mathrm{SL} \mathrm{VO}_{2 \max }\right) \text { and } \\
\text { hypoxia }\left(65 \% \text { altitude } \mathrm{VO}_{2 \max }\right)\end{array}$ & TA & 4300 & 10 days & $\begin{array}{l}\text { SL: } 0.95 \pm 0.01 \\
\mathrm{CH}: 0.94 \pm 0.02\end{array}$ \\
\hline $\begin{array}{l}\text { Katz and } \\
\text { Sahlin [8] }\end{array}$ & 8 (males) & $\begin{array}{l}5 \text { min exercise at } \\
\mathrm{SL}\left(49 \% \mathrm{SL} \mathrm{VO}_{2 \max }\right) \text { and } \\
\text { altitude }\left(67 \% \text { altitude } \mathrm{VO}_{2 \max }\right)\end{array}$ & $\mathrm{NH}$ & 4500 & $22 \mathrm{~min}$ & $\begin{array}{l}\text { SL: } 0.96 \pm 0.01 \\
\text { AH: } 1.10 \pm 0.04\end{array}$ \\
\hline $\begin{array}{l}\text { Kelly and } \\
\text { Basset [9] }\end{array}$ & 7 (males) & $\begin{array}{l}60 \text { min exercise at } \\
\mathrm{SL}\left(69 \% \mathrm{SL} \mathrm{VO}_{2 \max }\right) \text { and } \\
\text { altitude }\left(78 \% \text { altitude } \mathrm{VO}_{2 \max }\right)\end{array}$ & $\mathrm{NH}$ & 2750 & $180 \mathrm{~min}$ & $\begin{array}{l}\text { SL: } 0.92 \pm 0.05 \\
\text { AH: } 0.93 \pm 0.04\end{array}$ \\
\hline $\begin{array}{l}\text { Lundby and } \\
\text { Van Hall [10] A }\end{array}$ & $8($ male $=6$, female $=2)$ & $\begin{array}{l}60 \text { min cycling at } \\
\mathrm{SL}\left(46 \% \mathrm{SL} \mathrm{VO} \mathrm{V}_{2 \max }\right) \text { and } \\
\text { at altitude }\left(54 \% \mathrm{SL} \mathrm{VO}_{2 \max }\right)\end{array}$ & $\mathrm{NH}$ & 4100 & $70 \mathrm{~min}$ & $\begin{array}{l}\text { SL: } 0.91 \pm 0.01 \\
\text { AH: } 0.95 \pm 0.02\end{array}$ \\
\hline $\begin{array}{l}\text { Lundby and } \\
\text { Van Hall [10] B }\end{array}$ & $8($ male $=6$, female $=2)$ & $\begin{array}{l}60 \text { min cycling at } \\
\mathrm{SL}\left(46 \% \mathrm{SL} \mathrm{VO}_{2 \max }\right) \text { and } \\
\text { at altitude }\left(59 \% \text { altitude } \mathrm{VO}_{2 \max }\right)\end{array}$ & TA & 4100 & 28 days & $\begin{array}{l}\text { SL: } 0.91 \pm 0.01 \\
\text { CH: } 0.94 \pm 0.01\end{array}$ \\
\hline $\begin{array}{l}\text { Péronnet } \\
\text { et al. [11] }\end{array}$ & 5 (males) & $\begin{array}{l}80 \text { min cycling at } \\
\mathrm{SL}(54 \% \mathrm{SL} \text { max) and } \\
\left.\text { at altitude ( } 77 \% \text { altitude } \mathrm{VO}_{2 \max }\right)\end{array}$ & $\mathrm{HH}$ & 4300 & $110 \mathrm{~min}$ & $\begin{array}{l}\text { SL: } 0.92 \pm 0.02 \\
\text { AH: } 0.97 \pm 0.01\end{array}$ \\
\hline $\begin{array}{l}\text { Van Hall } \\
\text { et al. [12] }\end{array}$ & $6($ male $=5$, female $=1)$ & $\begin{array}{l}20 \text { min cycling at } \\
\mathrm{SL}\left(46 \% \mathrm{SL} \mathrm{VO}_{2 \max }\right) \text { and } \\
\text { altitude }\left(82 \% \text { altitude } \mathrm{VO}_{2 \max }\right)\end{array}$ & TA & 5620 & 63 days & $\begin{array}{l}\text { SL: } 0.92 \pm 0.02 \\
\text { CH: } 0.92 \pm 0.01\end{array}$ \\
\hline
\end{tabular}

Values presented as mean $\pm \mathrm{SD}$

$H H$ hypobaric hypoxia, $N H$ normobaric hypoxia, $T A$ terrestrial altitude, $S L$ sea level, $A H$ acute hypoxia, $C H$ chronic hypoxia

alter the overall mean difference. Inspection of the funnel plot and Egger's regression intercept revealed that there was little evidence of small study effects (intercept $=7.59,95 \%$ CI: -60.78 to $75.97 ; p=0.39$ ).

Hypoxic exposure resulted in a significant decrease in relative fat oxidation during exercise matched for absolute intensities, compared with normoxia (mean difference: $-12.7,95 \% \mathrm{CI}:-16.9$ to $-8.4 \% ; n=3, p<0.01$;
Additional file 3). The degree of heterogeneity was found to be high between studies $\left(I^{2}=95.94 \%, Q=49.27, \tau^{2}=\right.$ $13.02, d_{f}=2$ ). Sensitivity analysis revealed minor changes only, and these changes did not substantially alter the overall mean difference. Inspection of the funnel plot and Egger's regression intercept revealed that there was little evidence of small study effects (intercept $=-8.89$, 95\% CI: -72.57 to $54.80 ; p=0.33$ ).

Table 2 Summary of studies investigating the effect of hypoxia on substrate utilisation during exercise matched for absolute intensity

\begin{tabular}{|c|c|c|c|c|c|c|c|c|c|}
\hline \multirow[t]{2}{*}{ Study } & \multirow[t]{2}{*}{ Participants } & \multirow[t]{2}{*}{ Study design } & \multirow[t]{2}{*}{$\begin{array}{l}\text { Type of } \\
\text { hypoxia }\end{array}$} & \multirow[t]{2}{*}{$\begin{array}{l}\text { Altitude } \\
\text { (m) }\end{array}$} & \multirow{2}{*}{$\begin{array}{l}\text { Duration of } \\
\text { exposure }\end{array}$} & \multicolumn{2}{|c|}{$\begin{array}{l}\text { Absolute substrate } \\
\text { use }\left(\mathrm{g} \cdot \mathrm{min}^{-1}\right)\end{array}$} & \multicolumn{2}{|c|}{ Relative substrate use (\%) } \\
\hline & & & & & & $\begin{array}{l}\mathrm{CHO} \\
\text { oxidation }\end{array}$ & Fat oxidation & $\mathrm{CHO}$ oxidation & Fat oxidation \\
\hline $\begin{array}{l}\text { Braun } \\
\text { et al. [7] }\end{array}$ & 15 (females) & $\begin{array}{l}30 \text { min cycling at } \\
\mathrm{SL}\left(50 \% \mathrm{SL} \mathrm{VO}_{2 \max }\right) \text { and } \\
\text { hypoxia }\left(65 \% \text { altitude } \mathrm{VO}_{2 \max }\right)\end{array}$ & TA & 4300 & 10 days & $\begin{array}{l}\text { SL: } 1.38 \pm 0.08 \\
\mathrm{CH}: 1.22 \pm 0.09\end{array}$ & NM & NM & NM \\
\hline $\begin{array}{l}\text { Kelly and } \\
\text { Basset [9] }\end{array}$ & 7 (males) & $\begin{array}{l}60 \text { min exercise at } \\
\mathrm{SL}\left(69 \% \mathrm{SL} \mathrm{VO}_{2 \max }\right) \text { and } \\
\text { altitude }\left(78 \% \text { altitude } \mathrm{VO}_{2 \max }\right)\end{array}$ & $\mathrm{NH}$ & 2750 & $180 \mathrm{~min}$ & $\begin{array}{l}\mathrm{SL}: 2.27 \pm 0.57 \\
\mathrm{AH}: 2.30 \pm 0.50\end{array}$ & $\begin{array}{l}\mathrm{SL}: 0.46 \pm 0.18 \\
\mathrm{AH}: 0.34 \pm 0.21\end{array}$ & NM & NM \\
\hline $\begin{array}{l}\text { Lundby and } \\
\text { Van Hall [10] A }\end{array}$ & $\begin{array}{l}8(\text { male }=6 \\
\text { female }=2)\end{array}$ & $\begin{array}{l}60 \text { min cycling at } \\
\mathrm{SL}(46 \% \mathrm{SL} \text { VO2max) and at } \\
\left.\text { altitude ( } 54 \% \mathrm{SL} \mathrm{VO} \mathrm{O}_{2 \max }\right)\end{array}$ & $\mathrm{NH}$ & 4100 & $70 \mathrm{~min}$ & $\begin{array}{l}\mathrm{SL}: 2.00 \pm 0.20 \\
\mathrm{AH}: 2.50 \pm 0.20\end{array}$ & $\begin{array}{l}\text { SL: } 0.30 \pm 0.01 \\
\mathrm{AH}: 0.20 \pm 0.01\end{array}$ & $\begin{array}{l}\text { SL: } 73.90 \pm 2.00 \\
\text { AH: } 86.20 \pm 2.00\end{array}$ & $\begin{array}{l}\text { SL: } 26.10 \pm 2.00 \\
\mathrm{AH}: 13.80 \pm 2.00\end{array}$ \\
\hline $\begin{array}{l}\text { Lundby and } \\
\text { Van Hall [10] B }\end{array}$ & $\begin{array}{l}8(\text { male }=6 \\
\text { female }=2)\end{array}$ & $\begin{array}{l}60 \text { min cycling at } \\
\mathrm{SL}(46 \% \mathrm{SL} \text { VO2max) and at } \\
\left.\text { altitude ( } 59 \% \text { altitude } \mathrm{VO}_{2 \max }\right)\end{array}$ & TA & 4100 & 10 days & $\begin{array}{l}S L: 2.00 \pm 0.20 \\
C H: 2.30 \pm 0.10\end{array}$ & $\begin{array}{l}\text { SL: } 0.30 \pm 0.01 \\
C H: 0.20 \pm 0.01\end{array}$ & $\begin{array}{l}\text { SL: } 73.90 \pm 2.00 \\
\text { CH: } 82.20 \pm 2.20\end{array}$ & $\begin{array}{l}\text { SL: } 26.10 \pm 2.00 \\
C H: 17.80 \pm 2.20\end{array}$ \\
\hline $\begin{array}{l}\text { Péronnet } \\
\text { et al. [11] }\end{array}$ & 5 (males) & $\begin{array}{l}80 \text { min cycling at } \\
\mathrm{SL}(54 \% \mathrm{SL} \text { max) and at } \\
\text { altitude }\left(77 \% \text { altitude } \mathrm{VO}_{2 \max }\right)\end{array}$ & $\mathrm{HH}$ & 4300 & $110 \mathrm{~min}$ & $\begin{array}{l}\mathrm{SL}: 2.18 \pm 0.11 \\
\mathrm{AH}: 2.67 \pm 0.10\end{array}$ & $\begin{array}{l}\text { SL: } 0.32 \pm 0.08 \\
\mathrm{AH}: 0.10 \pm 0.03\end{array}$ & $\begin{array}{l}\mathrm{SL}: 75.30 \pm 5.20 \\
\mathrm{AH}: 92.00 \pm 2.10\end{array}$ & $\begin{array}{l}\mathrm{SL}: 24.70 \pm 5.20 \\
\mathrm{AH}: 8.00 \pm 2.10\end{array}$ \\
\hline $\begin{array}{l}\text { Van Hall } \\
\text { et al. [12] }\end{array}$ & $\begin{array}{l}6(\text { male }=5 \\
\text { female }=1)\end{array}$ & $\begin{array}{l}20 \text { min cycling at } \\
\mathrm{SL}\left(46 \% \mathrm{SL} \mathrm{VO}_{2 \max }\right) \text { and } \\
\text { altitude }\left(82 \% \text { altitude } \mathrm{VO}_{2 \max }\right)\end{array}$ & TA & 5620 & 63 days & $\begin{array}{l}\text { SL: } 2.22 \pm 0.34 \\
C H: 2.31 \pm 0.14\end{array}$ & NM & NM & NM \\
\hline
\end{tabular}




Study name
Braun et al, (2000)
Katz and Sahlin, (1987)
Kelly and Bassett, (2017)
Lundby et al, (2002) A
Lundby et al, (2002) B
Peronnet et al, (2006)
Van Hall et al, (2002)
Fig. $\mathbf{1}$ Forest plot of mean differences (means $\pm 95 \%$ Cl) for studies
investigating the effects of hypoxia on RER during exercise matched
for absolute intensities. The size of the square represents the relative
$\begin{aligned} & \text { weight of the trial. Cls are represented by a horizontal line through } \\ & \text { their representative circles. The diamond quantifies the overall mean } \\ & \text { difference (means } \pm 95 \% \text { Cl). A and B refer to the different trial arms } \\ & \text { of each study. Details of which are provided in Table 1 }\end{aligned}$

Mean difference, heterogeneity and sensitivity analysis for absolute carbohydrate and fat oxidation rates

Hypoxic exposure resulted in a non-significant increase in absolute carbohydrate oxidation rates during exercise matched for absolute intensities, compared with normoxia (mean difference $=0.21 \mathrm{~g} \cdot \mathrm{min}^{-1}, 95 \% \mathrm{CI}=-0.11$ to $0.53 ; n=6, p=0.19$; Fig. 2 ). The degree of heterogeneity was found to be high between studies $\left(I^{2}=98.69 \%\right.$, $\left.\mathrm{Q}=380.53, \mathrm{\tau}^{2}=0.15, \mathrm{~d}_{\mathrm{f}}=5\right)$. Sensitivity analysis revealed that the removal of one comparison by Braun et al. [7]

Study name
Braun et al, (2000)
Kelly and Bassett, (2017)
Lundby et al, (2002) A
Lundby et al, (2002) B
Peronnet et al, (2006)
Van Hall et al, (2002)
Fig. 2 Forest plot of mean differences (means $\pm 95 \%$ Cl) for studies
investigating the effects of hypoxia on absolute carbohydrate oxidation
during exercise matched for absolute intensities. The size of the square
represents the relative weight of the trial. Cls are represented by a
horizontal line through their representative circles. The diamond quantifies
the overall mean difference (means $\pm 95 \%$ Cl). A and B refer to the
different trial arms of each study. Details of which are provided in Table 2

increased the mean difference to $0.32 \mathrm{~g} \cdot \mathrm{min}^{-1}$ (95\% CI: 0.18 to $0.47 ; p=0.01)$. Inspection of the funnel plot and Egger's regression intercept revealed little evidence of small study effects (intercept $=7.95,95 \% \mathrm{CI}$ : -6.96 to 22.85; $p=0.21$ ).

Hypoxic exposure resulted in a significant reduction in absolute fat oxidation during exercise matched for absolute intensity, compared with normoxia (mean difference: $-0.11 \mathrm{~g} \cdot \mathrm{min}^{-1}$, $95 \% \mathrm{CI}:-0.12$ to $-0.09 ; n=4, p<$ 0.01 ; Fig. 3). The degree of heterogeneity was found to be high between studies $\left(I^{2}=85.85 \%, Q=21.20, \tau^{2}=\right.$ $\left.0.00009, d_{f}=3\right)$. Sensitivity analysis revealed minor changes only, and these changes did not substantially alter the overall mean difference. Inspection of the funnel plot and Egger's regression intercept revealed evidence of small study effects (intercept $=-2.64,95 \% \mathrm{CI}$ : -9.59 to $4.31 ; p=0.24$ ).

\section{Risk of bias}

Since many of the studies were high altitude expeditions, certain biases were often unavoidable such as blinding of participants and personnel (Fig. 4). However, it was deemed that some of these biases could not affect the outcome variable and were therefore classified as low risk. In addition, all included studies were not clinically registered, therefore it is not possible to determine if all outcome variables were reported, therefore selective reporting bias was listed as unclear.

\section{Discussion}

In response to Young et al. [1], the purpose of this manuscript was to examine the effects of hypoxic exposure on substrate oxidation during exercise matched for absolute intensities. Findings from this meta-analysis

Study name

Kelly and Bassett, (2017)

Lundby et al, (2002) A

Lundby et al, (2002) B

Peronnet et al, (2006)

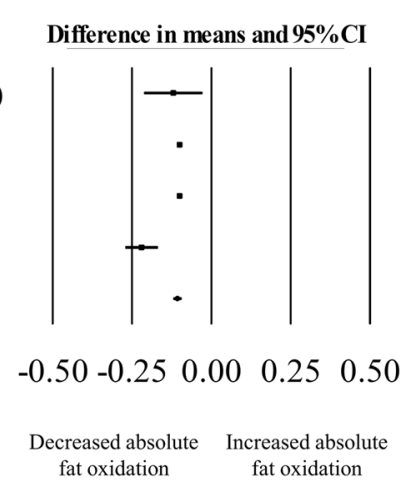

Fig. 3 Forest plot of mean differences (means $\pm 95 \% \mathrm{Cl}$ ) for studies investigating the effects of hypoxia on absolute fat oxidation during exercise matched for absolute intensities. The size of the square represents the relative weight of the trial. Cls are represented by a horizontal line through their representative circles. The diamond quantifies the overall mean difference (means $\pm 95 \% \mathrm{Cl}$ ). A and B refer to the different trial arms of each study. Details of which are provided in Table 2 


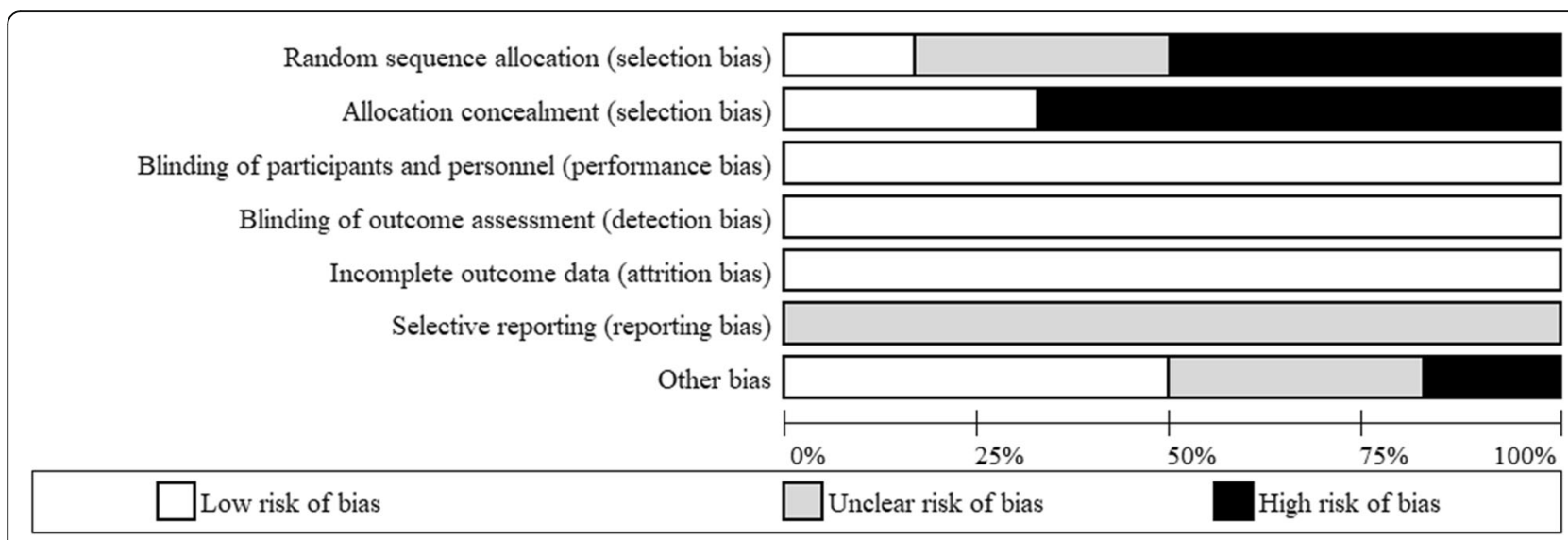

Fig. 4 Assessment of risk of bias (Cochrane's collaboration tool)

support those reported by Young et al. [1] but highlight some interesting discussion points. We observed an increased relative carbohydrate contribution to energy provision during exercise matched for absolute intensities in hypoxia compared with normoxia. A concurrent reduction in the relative contribution of fat to energy provision during exercise matched for absolute intensities was also observed. This effect was not moderated by any of the experimental characteristics included in this analysis, likely due to the dominant effect of an increased exercise stimulus. Notably, this contrasts our previously reported data demonstrating no difference in the relative contribution of carbohydrate or fat to energy provision during exercise matched for relative intensities in hypoxia compared with normoxia [2].

A greater RER and an increase in relative (but not absolute) carbohydrate oxidation were observed in hypoxia when exercise was matched for absolute intensities. These findings are likely due to the reduced $\dot{V} \mathrm{O}_{2 \max }$ experienced in hypoxia [13], and subsequent increase in relative exercise intensity for a given workload [10]. The physiological mechanisms associated with these changes in substrate oxidation are likely explained as per the normoxic response to increased exercise intensity, as detailed previously [2]. Interestingly, these data contrast with data reported by Young et al. [5] who observed no significant change in absolute whole body carbohydrate oxidation during exercise matched for absolute intensities in acute hypoxia (terrestrial altitude $\sim 4300 \mathrm{~m}$ ) compared with normoxia with supplementation of a glucose and fructose beverage. These findings are surprising given the aforementioned effect of an increased relative exercise intensity on substrate oxidation and demonstrate the need for further research to elucidate these responses.

At the time of analysis, the small number of studies investigating exogenous/endogenous carbohydrate oxidation meant these data were not appropriate for inclusion in a meta-analysis. Young et al. [1] summarised that exogenous carbohydrate oxidation may be suppressed during exercise matched for absolute intensities in acute hypoxia compared with normoxia, however due to the paucity of research in this area, this response remains to be established. However, recent data from O'Hara et al. [6] investigating substrate oxidation responses in females during exercise matched for relative intensities in hypoxia and normoxia may somewhat support this suppression of exogenous carbohydrate oxidation. The efficacy of carbohydrate supplementation to improve exercise performance is likely determined by our ability to oxidise exogenous carbohydrate sources. Thus, future research is required to determine this response and establish the performance effect of carbohydrate supplementation in hypoxia.

\section{Conclusions}

Previously unpublished data from our recent metaanalysis confirms evidence provided by Young et al. [1], in demonstrating an increased relative contribution of carbohydrate oxidation to energy provision during exercise matched for absolute intensities in hypoxia compared with normoxia. These data now provide a comparable dataset (relative vs. absolute intensities) for use by researchers and practitioners in the design of nutritional interventions for relevant populations.

\section{Supplementary information}

Supplementary information accompanies this paper at https://doi.org/10. 1186/s12970-019-0330-7.

Additional file 1. Summary of moderator variables from the metaregression model for RER in response to hypoxic exposure during exercise matched for absolute intensities.

Additional file 2. Forest plot of mean differences (means $\pm 95 \% \mathrm{Cl}$ ) for studies investigating the effects of hypoxia on relative carbohydrate oxidation during exercise matched for absolute intensities. The size of the square represents the relative weight of the trial. Cls are represented by a horizontal line through their representative circles. The diamond 
quantifies the overall mean difference (means $\pm 95 \% \mathrm{Cl}$ ). A and B refer to the different trial arms of each study. Details of which are provided in Table 2.

Additional file 3. Forest plot of mean differences (means $+95 \% \mathrm{Cl}$ ) for studies investigating the effects of hypoxia on relative fat oxidation during exercise matched for absolute intensities. The size of the square represents the relative weight of the trial. Cls are represented by a horizontal line through their representative circles. The diamond quantifies the overall mean difference (means $\pm 95 \% \mathrm{Cl}$ ). A and B refer to the different trial arms of each study. Details of which are provided in Table 2.

\section{Abbreviations}

AH: Acute hypoxia; $\mathrm{CH}$ : Chronic hypoxia; $\mathrm{CHO}$ : Carbohydrate; Cl: Confidence interval; HH: Hypobaric hypoxia; MD: Mean difference; $\mathrm{NH}$ : Normobaric hypoxia; NM: Not measured; RER: Respiratory exchange ratio; SD: Standard deviation; SL: Sea level; TA: Terrestrial altitude

\section{Acknowledgements}

Not applicable.

\section{Authors' contributions}

$\mathrm{AG}, \mathrm{JOH}, \mathrm{KD}$ and RK conceived and planned the study. AG, JM, OS and KD conducted the search and were involved in the review and extraction of all data. AG, JM and KD performed the analysis on the extracted data. All authors discussed the interpretation of results. AG wrote the manuscript. All authors provided critical feedback and helped shape the manuscript. All authors read and approved the final manuscript.

\section{Funding}

Not applicable.

\section{Availability of data and materials}

The data analysed and generated in this study are included in this published article and the associated additional files

\section{Ethics approval and consent to participate}

Not applicable.

\section{Consent for publication}

Not applicable.

\section{Competing interests}

The authors declare that they have no competing interests.

\section{Author details}

'Research Institute for Sport, Physical Activity and Leisure, Leeds Beckett University, Leeds LS6 3QS, UK. ${ }^{2}$ Human Nutrition Research Centre, Institute of Cellular Medicine, Newcastle University, Leech Building, Framlington Place, Newcastle Upon Tyne NE2 4HH, UK. ${ }^{3}$ School of Clinical and Applied Science, Leeds Beckett University, Leeds LS1 3HE, UK.

Received: 10 October 2019 Accepted: 10 December 2019

Published online: 19 December 2019

\section{References}

1. Young A, Margolis L, Pasiakos S. Commentary on the effects of hypoxia on energy substrate use during exercise. J Int Soc Sports Nutr. 2019:16:28.

2. Griffiths A, Shannon O, Matu J, King R, Deighton K, O'Hara J. The effects of environmental hypoxia on substrate utilisation during exercise: a metaanalysis. J Int Soc Sports Nutr. 2019;16:10.

3. Fulco CS, Rock PB, Cymerman A. Maximal and submaximal exercise performance at altitude. Aviat Space Environ Med. 1998;69(8):793-801.

4. Vanhatalo A, Fulford J, Bailey S, Blackwell J, Winyard P, Jones A. Dietary nitrate reduces muscle metabolic perturbation and improves exercise tolerance in hypoxia. J Physiol. 2011;589:5517.

5. Young A, Berryman C, Kenefick R, Derosier A, Margolis L, Wilson M, Carrigan T, Murphy N, Carbone J, Rood J, Pasiakos S. Altitude acclimatization alleviates the hypoxia-induced suppression of exogenous glucose oxidation during steady-state aerobic exercise. Front Physiol. 2018;9:830.
6. O'Hara JP, Duckworth L, Black A, Woods D, Mellor A, Boos C, Gallagher L, Tsakirides C, Arjomandkhah NC, Morrison D, et al. Fuel use during exercise at altitude in women with glucose-fructose ingestion. Med Sci Sports Exerc. 2019:51:2586.

7. Braun B, Mawson J, Muza SR, Dominick S, Brookes G, Horning M, Rock PB, Moore L, Mazzeo R, Ezeji-Okoye S, Butterfield G. Women at altitude. Carbohydrate utilisation during exercise at 4300m. J Appl Physiol. 2000;88: 246-56.

8. Katz A, Sahlin K. Effect of decreased $\mathrm{O} 2$ availability on $\mathrm{NADH}$ and lactate contents in human skeletal muscle during exercise. Acta Physiol Scand. 1987;131:119-27.

9. Kelly LP, Basset FA. Acute normobaric hypoxia increases post-exercise lipid oxidation in healthy males. Front Physiol. 2017:8:293.

10. Lundby C, Van Hall G. Substrate utilization in sea level residents during exercise in acute hypoxia and after 4 weeks of acclimatization to $4100 \mathrm{~m}$. Acta Physiol Scand. 2002;176:195-201.

11. Péronnet F, Massicotte D, Folch N, Melin B, Koulmann N, Jimenez C, Bourdon L, Launay JC, Savourey G. Substrate utilization during prolonged exercise with ingestion of 13C-glucose in acute hypobaric hypoxia $(4,300$ m). Eur J Appl Physiol. 2006;97:527-34.

12. Van Hall G, Calbet JA, Sondergaard H, Saltin B. Similar carbohydrate but enhanced lactate utilization during exercise after 9 wk of acclimatization to 5,620 m. Am J Physiol Endocrinol Metab. 2002;283:E1203-13.

13. Dill DB, Edwards HT, Folling A, Oberg AM, Pappenheimer AM, Talbott $J \mathrm{H}$. Adaptations of the organism to changes in oxygen pressure. J Physiol. 1931;71

\section{Publisher's Note}

Springer Nature remains neutral with regard to jurisdictional claims in published maps and institutional affiliations.

\section{Ready to submit your research? Choose BMC and benefit from:}

- fast, convenient online submission

- thorough peer review by experienced researchers in your field

- rapid publication on acceptance

- support for research data, including large and complex data types

- gold Open Access which fosters wider collaboration and increased citations

- maximum visibility for your research: over $100 \mathrm{M}$ website views per year

At $\mathrm{BMC}$, research is always in progress.

Learn more biomedcentral.com/submission 